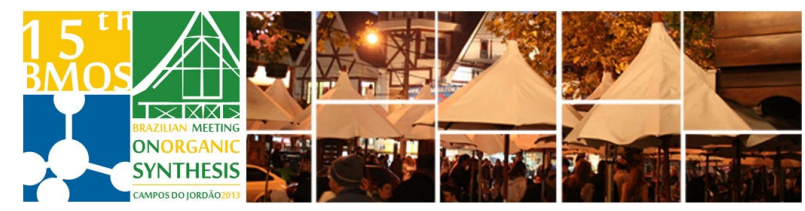

\title{
The oxidation of indole derivatives using dimethyl dioxirane
}

\author{
Luisa L. Marçal* (PG), Simon J. Garden (PQ) \\ Instituto de Química, Universidade Federal do Rio de Janeiro, CT, Bloco A, \\ Cidade Universitária - Ilha do Fundão, 21949-900 - Rio de Janeiro - RJ \\ *luisamarcal@ufrj.br and garden@iq.ufrj.br
}

Keywords: Tryptophan, Pictet-Spengler, spiro-pyrrolidine-2-oxindole

\section{INTRODUCTION}

The oxidation of indoles is an important route for the formation of oxindoles. Popular methods employ DMSO/HCl, $\quad N$-halosuccinimides or $t$-BuOCl. ${ }^{1}$ Additionally, 2,3-disubstituted indoles undergo oxidative rearrangement to give spiro-pyrrolidine-2oxindoles, a heterocyclic framework found in natural products and some currently interesting pharmaceutical compounds. ${ }^{2}$

The present study has investigated the use of dimethyl dioxirane (DMD) as an agent for promoting the oxidative rearrangement of tetrahydro- $\beta$ carbolines to spiro-pyrrolidine-2-oxindoles.

\section{RESULTS AND DISCUSSION}

$\mathrm{N}-\mathrm{H}$ indole substrates $(\mathbf{1}, \mathbf{2}$ and $\mathbf{3})$ were reacted with $\mathrm{DMD}$ generated in situ from $\mathrm{NaHCO}_{3}$ and oxone ${ }^{\circledR}$ in acetone $/ \mathrm{H}_{2} \mathrm{O}$ (Figura 1) and gave products 4 and 5 .

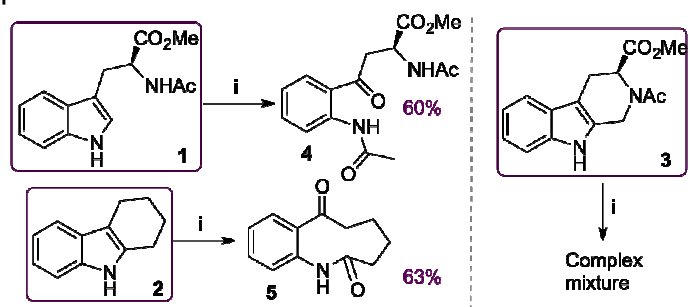

$\mathrm{i}_{2} \mathrm{O}$ /acetone, oxone, $\mathrm{NaHCO}_{3}$ r.t. / $30 \mathrm{~min}$

Figura 1. Oxidation of 1, 2 and $\mathbf{3}$ with DMD.

Pictet-Spengler (PS) reactions: ${ }^{3}$ Compounds 3 , 6, 7 and 8 were prepared by the PS reaction using tryptophan methyl ester (9): 3 by the reaction with formaldehyde (10), 6 and 7 using 2-oxoglutaric acid $(11),{ }^{5}$ and 8 by use of levulinic acid (12) ${ }^{6}$ (Figure 2).

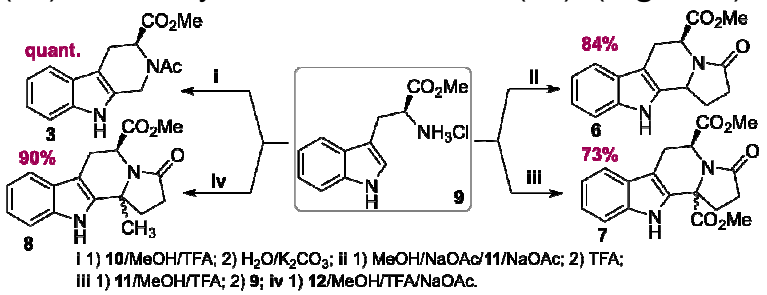

Figure 2. Preparation of tetrahydro- $\beta$-carbolines by the Pictet-Spengler reaction.

In view of the results of the oxidation of $\mathrm{N}-\mathrm{H}$ indoles a second approach where $\mathrm{N}$-acetyl indoles were treated with DMD (Figure 3) was investigated.

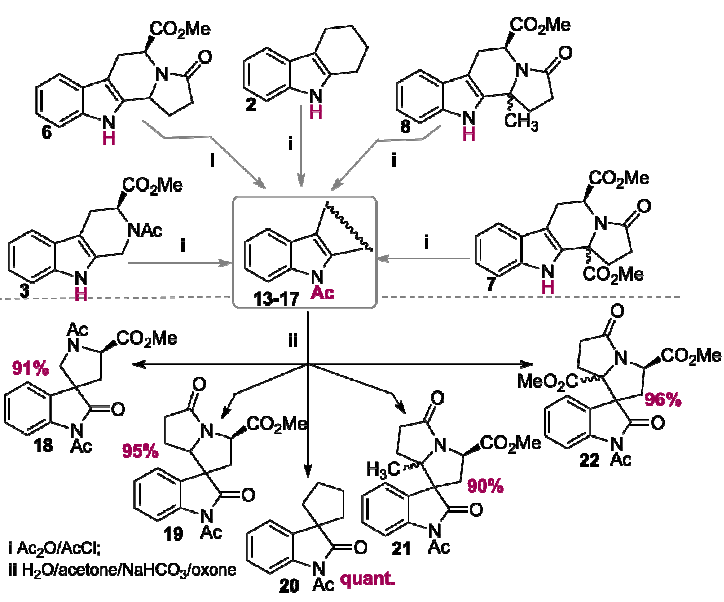

Figure 3. Spiro-Pyrrolidine-2-oxindoles from oxidative rearrangement of $\mathrm{N}$-acetylindoles with DMD.

\section{CONCLUSION}

The oxidation of $\mathrm{N}-\mathrm{H}$ indoles by DMD resulted in indole ring cleavage, as characterized by the products 4 (60\%) and 5 (63\%). The Pictet-Spengler reaction provided excellent yields of 3 (quant.), 6 $(84 \%), 7(73 \%)$ and $8(90 \%)$. The tetrahydro- $\beta$ carboline derivatives were acetylated to give 13 to 17. The $N$-acetylindoles reacted with DMD to give spiro-pyrrolidinyl-oxindoles as mixtures of diastereoisomers (except for 20) via an oxidative rearrangement: 18 (91\%), 19 (95\%), 20 (quant.), 21 $(90 \%)$ and 22 (96\%).

\section{ACKNOWLEDGEMENTS}

FAPERJ, CAPES, CNPq and PGQu-IQ-UFRJ

\section{REFERENCES}

${ }^{1}$ a) Savige, W. E.; Fontana, A. J. Chem. Soc., Chem. Commun. 1976, 599. b) Hinman, R. L.; Bauman, C. P. J. Org. Chem. 1964, 29, 1206. c) Shavel, J., Jr.; Zinnes, H. J. Am. Chem. Soc. 1962, 84,1320

2 a) Galliford, C. V.; Scheidt, K. A. Angew. Chem., Int. Ed. 2007, 46, 8748. b) Zhou, F.; Liu, Y.; Zhou, J. Adv. Synth. Catal. 2010 352, 1381.

${ }^{3}$ Cox, E. D.; Cook, J. M. Chem. Rev. 1995, 95, 1797.

${ }^{4}$ Hagen, T. J.; Guzman, F.; Schultz, C.; Cook, J. M.; Skolnick, P.; Shannon, H. E. Heterocycles 1986, 24, 2845

${ }^{5}$ a) Irikawa, H.; Toyoda, Y.; Kumagai, H.; Okumura, Y. Bull. Chem. Soc. Jpn. 1989, 62, 880. b) Soerens, D.; Sandrin, J.; Ungemach, F.; et al. J. Org. Chem. 1979, 44, 535

${ }^{6}$ Irikawa, H.; Toyoda, Y.; Kumagai, H.; Okumura, Y. Bull. Chem. Soc. Jpn. 1989, 62, 880 . 